\title{
LOS ACTOS DE HABLA EN LAS CARTAS A LA COLUMNA DE LANACIÓN
}

\section{THE SPEECH ACTS IN LA NACION'S LETTERS TO THE EDITOR}

\author{
Dorde Cuvardic García*
}

RESUMEN

Las Cartas al editor es una modalidad de periodismo participativo que permite el establecimiento de vínculos comunicativos entre los lectores, los medios periodísticos y los demás actores del espacio público de discusión. En este artículo se realiza un análisis de las Cartas a la columna de La Nación (nombre que tienen las cartas al editor en este periódico) desde la teoría pragmática de los actos de habla. El interés se centra en establecer las intenciones de los lectores que envían mensajes al diario.

PALABRAS CLAVE: COSTA RICA * MEDIOS COMUNICACIÓN * PRAGMÁTICA * ACTOS DE HABLA * CARTAS AL EDITOR * PERIODISMO PARTICIPATIVO

\section{ABSTRACT}

Letters to the editor is a modality of participative journalism that allows the establishment of communicative bonds among readers, media and other actors of the public space of discussion. In this article an analysis of Letters to the column of $L a$ Nación is made from the pragmatic theory of the speech acts. Interest is centered in establishing the intentions of the readers who send these messages to the newspaper.

KEYWORDS: COSTA RICA * MASS MEDIA * PRAGMATICS * SPEECH ACTS * LETTERS TO THE PUBLISHER * PARTICIPATIVE JOURNALISM

Antes del auge del periodismo participativo provocado por la aparición de las nuevas tecnologías, en pocas ocasiones las audiencias podían intervenir en el contenido de los medios de comunicación de masas. Las escasas excepciones, antes de la aparición de Internet, eran los períodos de preguntas en los programas televisivos o las opiniones emitidas en

Escuela de Filología y Escuela de Comunicación Colectiva, ambas de la Universidad de Costa Rica. dcuvardic@yahoo.es 
las denominadas Cartas al editor. El objetivo de este artículo es, precisamente, analizar la participación de los lectores en este último genero periodístico, de consolidada tradición en el ámbito de la prensa. Las más representativas, en Costa Rica, proceden de La Nación, cuyo nombre es Cartas a la columna. Su naturaleza es muy diferente a las publicadas en el Diario Extra, que presenta, a diferencia del primer diario, problemáticas privadas e íntimas.

\section{INTRODUCCIÓN: RADIOGRAFÍA DE UN GÉNERO DE OPINIÓN}

El enunciador del texto argumentativo de la Cartas al editor (término que será empleado a partir de ahora, por ser más conocido) es presentado por la empresa periodística como un lector regular del diario al que se ofrece espacio para emitir su opinión sobre las problemáticas sociales. Puede enunciar su discurso tanto a título individual como institucional. Argumentará sobre acontecimientos de la esfera pública, es decir, que incidan en la colectividad y no estrictamente en la intimidad de los ciudadanos. Debe recuperarse la importancia de la Carta al editor o director como indicador de la relevancia que el periódico asigna a un referente social. Cuando en la fase álgida de un conflicto aparecen cartas al editor, editoriales, columnas y artículos que comentan un referente social, esto significa que el medio de comunicación le está asignando una alta relevancia. Contribuye a definirlo como de interés general. Es decir, la problemática tiene un nivel tal de relevancia social que el periódico considera importante que sea discutido en sus géneros de opinión, entre ellos, las cartas al editor.

En todo caso, la carta al editor no se encuentra sometida al régimen de actualidad tan férreamente como la caricatura o el editorial. Entre el proceso de redacción de una carta por parte de un lector y su publicación en la prensa puede establecerse una disonancia temporal de varios días o semanas.

Las preguntas que tratamos de responder en este artículo son: ¿Qué intención o propósito tiene el lector al expresar su opinión sobre el acontecer público? ¿A quién se dirige? ¿Cómo pretende incidir la lectora o el lector en la evolución del acontecer social? Responderemos estas preguntas al realizar un análisis de las cartas de La Nación desde la teoría de los actos de habla.

\section{ESTADO DE LA CUESTIÓN}

En comparación con los géneros informativos, los géneros de opinión de la prensa escrita han obtenido escasa atención por parte de los investigadores en comunicación. Y, dentro de este último ámbito discursivo, el interés por analizar las llamadas cartas al editor ha sido todavía menor.

Han sido investigadas, sobre todo, en el ámbito anglosajón. Con la excepción de Policing the crisis, de Hall et ál. (1978), se han presentado la mayor parte de las investigaciones en Journalism Quarterly, una de las revistas especializadas en periodismo de mayor tradición. Los análisis revisados tienen por objeto de estudio el proceso de producción, la propuesta discursiva o ciertas problemáticas de la recepción de las cartas al editor. Así, por ejemplo, dentro de la tradición de los estudios de gatekeeping, Cozort Renfro (1979) analizó el proceso de selección de las cartas al editor al comparar las recibidas con las finalmente publicadas; determinó que los editores tratan de correlacionar los niveles de relevancia otorgados a los temas de las cartas con los niveles de relevancia asignados a los temas de las secciones informativas, con lo que se produce un proceso de agendasetting a nivel intramediático (la selección de temas informativos es un determinante de la selección de los temas de las cartas).

Por su parte, Forsythe (1950) construyó el perfil sociodemográfico de los remitentes de cartas publicadas en un diario de Kentucky: eran de edad madura o ancianos; hombres; conservadores hacia el matrimonio, las relaciones familiares, la esfera religiosa y la política; de educación formal superior al promedio; caucásicos; residentes por lo menos 18 años en la localidad donde vivían; miembros de profesiones de 'cuello blanco'; y, por último, concentraban sus cartas en ciertos temas (cuando enviaban más de una)... En Costa Rica también se pueden investigar este tipo de perfiles. 
Singletary (1976), en otra de las escasas investigaciones en recepción, se ocupó de indagar en las pautas de lectura de las cartas al editor, así como en la apreciación que tienen los lectores sobre su importancia: un 33\% de la muestra leía las cartas casi siempre; un 7,1\% envió una carta por lo menos una vez; un $32 \%$ criticaría fuertemente la desaparición de esta sección de los periódicos; la mitad de la muestra leía la totalidad de una carta y un 48 \% creía que los editores publicaban las cartas sin cambios importantes. El interés del lector costarricense por las cartas también puede ser indagado.

Por su parte, Lemert y Larkin (1979) explicaron las causas que limitan la presencia de información movilizadora (movilizing information, que permite al lector tomar acciones, movilizarse) en las cartas al editor, entre ellas, el mayor rechazo de los editores ante cartas que incorporen este tipo de información, así como la anuncia de los remitentes a no incorporarla por la expectativa de un posible rechazo. Por otra parte, una investigación futura podría dedicarse al desempeño de los editores de las cartas en la prensa costarricense. Se podrían formular preguntas como las siguientes: ¿Hay un editor encargado de las cartas?; ¿Cuántas cartas llegan cada día?; ¿Cuántas llegan por apartado postal, por fax y por correo electrónico?; ¿Qué criterios de selección siguen?; ¿Buscan publicar la mayor diversidad de temas posibles?; ¿Excluyen los ataques personales?; ¿El título de las cartas es elegido por el editor?

Por su parte, Hall et ál. (1978: 120-1) analizan el proceso productivo de las cartas al editor en Gran Bretaña y concluyen que son sometidas a un proceso de selección determinado por la imagen social que la empresa periodística tiene de sí misma; además, en lugar de representar fidedignamente a la opinión pública, más bien ayudan a la prensa a organizar y orquestar la discusión sobre los asuntos públicos.

En EE.UU. los investigadores han establecido que la procedencia de los lectores está en cierta medida limitada. Parte de las cartas al editor proceden de actores sociales institucionales que, en otras oportunidades, aparecen regularmente en las noticias citadas como fuentes. Así lo señalan Ericson et ál. (1989: 32) en un importante estudio el proceso productivo periodístico; concluyen que [muchas] "cartas proceden de fuentes que están regularmente en las noticias. Nuestra tesis es que, como tales, las cartas son manejadas por las organizaciones informativas simplemente como otro tipo de entrada de las fuentes, sólo que en este caso proporcionan el 'manuscrito preparado' ('filed copy') en forma de carta.

Un análisis cuantitativo diacrónico realizado en Costa Rica nos permitiría indagar en la procedencia de los remitentes de las cartas y apreciar si la situación es similar a la estadounidense.

\section{METODOLOGÍA}

Hemos elegido analizar las cartas al editor publicadas en La Nación del domingo 7 de octubre del 2008. Este día se publicaron diez cartas. El corpus se ha elegido a conveniencia: El domingo se publican más cartas y elegir este día permite analizar mayor cantidad de textos con objetivos diferentes. Interesa, más que todo, realizar un análisis textual cualitativo orientado a comprender cómo los enunciadores de las cartas expresan, desde la teoría de los actos de habla, sus intenciones u objetivos ante los destinatarios. Desde la teoría de los actos de habla, señalan Calsamiglia y Tusón (2004: 197), se establece que "las palabras, además de su significado referencial, literal, constituyen una forma de acción intencional cuando son pronunciadas" (en cursiva en el original). Es decir, los lectores tienen ciertas intenciones o propósitos al escribir cartas a La Nación. Cuando el ser humano emite enunciados, lleva a cabo acciones y, además, pretende que sus destinatarios cumplan acciones comunicativas (responder, por ejemplo) o ejecutivas (mover una silla o cerrar una puerta, por ejemplo).

La teoría de los actos de habla analiza los enunciados desde tres niveles de análisis. En primer lugar, los analiza como actos locutivos, es decir, como enunciados que cuentan con cierta estructura gramatical. Por ejemplo, el análisis del acto locutivo establecería que 'Cierra la puerta' es un enunciado imperativo. 
El segundo nivel de análisis radica en establecer el acto ilocutivo o la acción verbal que llevada a cabo al expresar el enunciado. Se analiza la intencionalidad o finalidad que tiene el enunciador al emitirlo. En el ejemplo 'Cierra la puerta', el acto ilocutivo que se lleva a cabo es una orden. Los enunciados cuentan con una fuerza ilocutiva que determina como serán recibidos por los destinatarios: como orden, afirmación, etc. Para determinar el acto ilocutivo proferido en el enunciado, el analista debe reconocer el verbo que, implícita o explícitamente, determina su intencionalidad. Por ejemplo, en Cierra la puerta podemos inferir que el enunciado es una orden si hacemos explícito el verbo que orienta el enunciado: Te ordeno que + cierres la puerta.

En el tercer nivel de análisis, los enunciados se analizan como actos perlocutivos. Se determinan las consecuencias que, desde las intenciones del enunciador, el acto de habla expresado podría tener en el destinatario, consecuencias tanto verbales - obtener una repuesta- como ejecutivas - cumplir la orden proferida por el enunciador.

En resumen: en el enunciado 'Cierra la puerta', el acto locutivo es el imperativo proferido, el acto ilocutivo es la enunciación de la orden y el acto o efecto perlocutivo las consecuencias previsibles del enunciado en el destinatario (Hernández, 2006: 259).

Para que el discurso obtenga consecuencias en el destinatario desde las intenciones del enunciador deben darse las condiciones comunicativas apropiadas, las llamadas condiciones de éxito de los enunciados [felicity conditions]: que las personas protagonistas del intercambio comunicativo y las circunstancias temporales $y$ espaciales sean las apropiadas; que el enunciado sea expresado con las palabras pertinentes y con sinceridad; que el procedimiento para expresarlo sea el correcto; que el procedimiento se de en todos sus pasos; que los participantes tengan la disposición para asumir el procedimiento que debe seguirse en el intercambio comunicativo; $y$ que tengan en el futuro la intención de comportarse de acuerdo con el enunciado expresado (Austin, 1998: 49-52; Calsamiglia y Tusón, 2004; 197; García Negroni y Tordesillas Colado, 2001: 118 y 119). Por ejemplo, para que el intercambio verbal proferido en una boda tenga éxito, los participantes deben reunir los requisitos para protagonizarlo: deben ser solteros. A su vez, para que la orden de un directivo a un empleado sea 'exitosa' y sea ejecutada, el primero debe encontrarse investido de la autoridad pertinente para impartir órdenes en una organización, mientras que el empleado deberá tener la intención de ejecutarla.

Para realizar el análisis, nos vamos a servir de la tipología de John Searle, que ofreció por primera vez en 1976 en su artículo The classification of illocutionary acts, en el número 5 de la revista Language in Society, muy similar a la ofrecida previamente por John Austin. Los analistas utilizan, por lo general, la propuesta del primer investigador. Esta última se encuentra explicada, por lo demás, en los manuales de Calsamiglia y Tusón (2004: 197) y de García Negroni y Tordesillas Colado (2001: 136-138).

Un primer tipo de acto de habla es el asertivo o representativo. El enunciador propone, en este acto de habla, una verdad referencial. Enunciados asertivos serán, por ejemplo, las afirmaciones, las explicaciones, las clasificaciones, las descripciones, los diagnósticos, las certificaciones. Un acto de habla asertivo será reconocido en aquel enunciado que implícita o explícitamente utilice verbos como afirmar, certificar, anunciar, predecir... El discurso informativo periodístico es un gran macroacto de habla asertivo, ya que pretende demostrar la veracidad de acontecimientos descritos o narrados provenientes del mundo social, veracidad casi siempre respaldada por el público.

Un segundo tipo de acto de habla es el directivo. Cuando lo emite, su enunciador pretende provocar la actuación ejecutiva del destinatario. Enunciados directivos son las órdenes, los mandatos, los consejos, las preguntas, las prohibiciones, las recomendaciones... Un acto de habla directivo será reconocido cuando implícita o explícitamente se utilicen verbos como preguntar, pedir, prohibir, exigir, encargar, ordenar. Del discurso publicitario, panorámicamente entendido, se dice que es un gran macroacto de habla directivo, ya que su enunciador pretende en última instancia que el destinatario realice el acto de compra de los bienes de consumo. 
Un tercer tipo de acto de habla es el promisorio, también llamado compromisorio o comisivo. Cuando lo emite, el enunciador se compromete a realizar una conducta futura. Enunciados promisorios son las ofertas, las promesas, los juramentos, las amenazas. Un acto de habla promisorio será reconocido cuando implícita o explícitamente se utilicen verbos como ofrecer, prometer, jurar, amenazar.

Un cuarto tipo de acto de habla es el expresivo. Cuando lo emite, el destinador se compromete a expresar su estado psicológico. Un acto de habla expresivo será reconocido cuando implícita o explícitamente se utilicen verbos como sentir, pedir perdón, agradecer, perdonar, felicitar.

Por último, un quinto tipo de acto de habla es el declarativo. Cuando lo emite, el enunciador, institucionalmente legitimado, pretende provocar cambios en las relaciones sociales. Sistemas normativos como el derecho, la iglesia, el Estado o las empresas privadas provocan la respuesta de los destinatarios a los que se dirigen en términos verbales o ejecutivos. Por ejemplo, declarar una guerra tiene como consecuencia la movilización del ejército. Un acto de habla declarativo se reconoce cuando implícita o explícitamente se utilicen verbos como sentenciar, bautizar, vetar, declarar una guerra, levantar una sesión.

En este análisis, a la hora de inferir la intencionalidad última buscada por el enunciador debemos investigar también los actos de habla indirectos, "en los que al significado literal del acto locutivo hay que sumar un significado añadido a través de la fuerza ilocutiva" (en cursiva en el original) (Calsamiglia y Tusón, 2004: 198). Por ejemplo, un acto de habla ilocutivo directivo se puede expresar mediante una aserción que sea reconocida por el destinatario como orden. 'Son las cinco' es un enunciado cuyo significado literal permite comprenderlo como acto de habla asertivo, pero si es expresado por el gerente de un comercio al empleado, puede interpretarse como 'Ya puedes cerrar el local', es decir, como acto de habla directivo. El acto de habla directivo se expresó indirectamente mediante una afirmación.

La propuesta de los actos de habla es emergente. Prácticamente todo manual de análisis del discurso, por lo demás, incorpora un capítulo o tema a esta corriente de la pragmática (este es el caso, por citar unos pocos casos, Calsamiglia y Tusón, 2004; Maingueneau, 1976; Schiffrin, 1994). La mayor parte de los análisis de los actos de habla se orientan hacia la comunicación oral, aunque también han aparecido análisis aplicados al discurso verbal publicitario (Lineros, 1998), a la imagen, en los llamados actos de habla visuales (Pericot, 2002), así como a los textos periodísticos. En este último caso, Núñez, (2000) ha analizado los actos de habla en los textos del Ombudsman (el defensor de los lectores) del diario El Nacional de Venezuela. Concluye que el Defensor utiliza actos de habla para mitigar los reclamos hechos por los lectores; así, utiliza actos de habla expresivos para agradecer, reconocer y pedir disculpas, con lo que se mitigan las quejas; compromisorios, que abren la posibilidad de solucionar los reclamos (aunque la verificación de las promesas, en el futuro, es prácticamente imposible); y asertivos, que permiten justificar las faltas periodísticas que provocaron las quejas de los lectores.

Utilizamos la teoría de los actos de habla para determinar sistemáticamente el propósito o intención que los lectores expresan en sus cartas ante el acontecer social. Así podrá evitarse la formulación de tipologías más impresionistas cuyas categorías muchas veces se traslapan.

Por ejemplo, para el caso de la radio, Herrera (2003: 145-166), considera que desde el contenido de la participación de la audiencia, se puede realizar una clasificación desde la finalidad de la intervención: (1) expresar una opinión, (2) rectificar una información, (3) relatar un caso propio o ajeno, (4) consultar una información, (5) denunciar un hecho o situación, (6) desahogarse, (7) pedir información u opinión y, (8) por último, concursar. Por su parte, Winocur (2002: 90) también propone una tipología de la participación, también de los oyentes de radio; los objetivos de estos últimos son, según esta investigadora, (1) participar en un concurso, (2) solicitar información, (3) pedir asesoramiento legal o psicológico, (4) exponer una denuncia por abuso de autoridad, (5) comunicar una falla, ausencia o ineficiencia de un servicio público, (6) criticar la actuación de un funcionario público, (7) opinar sobre política o economía. 
Al carecer de un único punto de vista que estructure estas participaciones, se observa que muchas de las categorías se superponen. Por ejemplo, en la tipología de Herrera Damas, relatar una experiencia propia o ajena, también puede formar parte de una participación orientada a denunciar un hecho, o a desahogarse. Por otra parte, en la tipología de Winocur, podríamos inferir que exponer una denuncia por abuso de autoridad y criticar la actuación de un funcionario público pertenecen a la misma categoría. Consideramos que la teoría de los actos de habla permite estructurar una tipología de participación de las audiencias de categorías mutuamente excluyentes.

\section{ANÁLISIS DE LAS CARTAS A LA COLUMNA DE LA NACIÓN}

Esta sección ofrece al lector las modalidades o canales de comunicación para enviar cartas a la redacción. Aparece un apartado postal (10138-1000), un fax (2247 5022) y un correo electrónico <ellectorpregunta@nacion. com>

Además, esta sección también incorpora reglas sobre el formato de las cartas: 'No deben sobrepasar las 70 palabras'. También se añaden los datos que debe ofrecer el remitente (las cartas 'deben incluir el nombre con dos apellidos, lugar de residencia, fotocopia de la cédula y número de teléfono del remitente'). Asimismo, se menciona la existencia de un proceso de selección de las cartas antes de quedar publicadas: 'Nos reservamos el derecho de editar o no publicar cartas por extensas, de tema repetido o por extemporáneas, entre otras razones'. Para mantener la privacidad de los remitentes, su nombre no aparece en esta investigación.

La brevedad de las cartas nos permite reproducirlas completas y proceder, posteriormente, a su análisis.

\section{Carta número 1: El azul de la bandera}

Los colores de nuestra bandera se tomaron de los de la de Francia y cada uno tiene su significado. Así, el azul —azul celeste- simboliza el cielo patrio. ¿Por qué permitirnos que, en cada festividad patria, nos inunden el mercado con banderas con un color azul oscuro que no es el de la bandera? Ese supuesto azul se asemeja más al negro; es, como lo llama un colega ingeniero, 'azul tormentoso'.

Se critica el uso del color azul oscuro, $y$ no del celeste, en la bandera nacional. En primer lugar se emplea un asertivo; es decir, se certifica un hecho: Afirmo que + Los colores de nuestra bandera se tomaron de los de la de Francia y cada uno tiene su significado. Así, el azul —azul celeste - simboliza el cielo patrio. El verbo que permite inferir que este enunciado es un acto de habla asertivo es afirmar.

Seguidamente se plantea un acto de habla indirecto, un directivo (que aparece indirectamente), mediante una pregunta retórica: "¿Por qué permitirnos que, en cada festividad patria, nos inunden el mercado con banderas con un color azul oscuro que no es el de la bandera?" Está claro que para el enunciador no hay dilema para esta pregunta: la única respuesta posible es no; en caso contrario se estaría utilizando erróneamente un símbolo patrio. El acto directivo, si lo quisiéramos expresar directamente, se puede formular sin la pregunta retórica: No debemos permitir que el mercado quede inundado de banderas de color azul oscuro.

Por último, aparece un asertivo: "Ese supuesto azul se asemeja más al negro; es, como lo llama un colega ingeniero, 'azul tormentoso"'. Esta afirmación final se utiliza para confirmar, por énfasis, la afirmación de que el empleo del azul oscuro supone un uso erróneo de la bandera: 'se asemeja más al negro'. La carta define una situación como errónea (asertivo) y plantea, indirectamente que, como tal, desaparezca (directivo). El efecto perlocutivo, si la recomendación es asumida, radicaría en que las fábricas confeccionen banderas con azul celeste.

\section{Carta número 2: Ahorros detenidos}

El 7 de agosto solicité a BN Vital un retiro parcial de mi fondo de pensiones. Después de someterme al engorroso trámite de espera para recibir el dinero $y$ de estar indagando en el Banco Nacional, me 
informan casi 2 meses después que la Supen aún no les envía la autorización. Como cliente de años del fondo voluntario de pensiones complementarias, pregunto a Tributación Directa, Supen y BN Vital: ¿no creen que están reteniendo indebidamente nuestro dinero, voluntariamente ahorrado?

Comienza con un acto de habla asertivo: "El 7 de agosto solicité a BN Vital un retiro parcial de mi fondo de pensiones. Después de someterme al engorroso trámite de espera para recibir el dinero y de estar indagando en el Banco Nacional, me informan casi 2 meses después que la Supen aún no les envía la autorización". Se expone una situación.

A continuación se enuncia una queja, un acto de habla expresivo, aunque indirectamente, ya que literalmente aparece el acto de habla directivo de la pregunta retórica cortés. La cortesía es uno de los principales procedimientos lingüísticos de la comunicación pública: "Como cliente de años del fondo voluntario de pensiones complementarias, pregunto a Tributación Directa, Supen y BN Vital: ¿no creen que están reteniendo indebidamente nuestro dinero, voluntariamente ahorrado?". Se realiza una queja: tardar dos meses para informar, además, que un trámite no puede ejecutarse, atenta contra los derechos del cliente.

$\mathrm{El}$ acto de habla expresivo (queja) puede formularse con el verbo explícito: Me quejo + porque las instituciones bancarias retienen indebidamente nuestro dinero. Se puede inferir, además, un acto de habla directivo implícito o indirecto que motiva en realidad el envío de la carta al periódico. Estaría formulado de la siguiente manera: Las instituciones bancarias deben modificar sus reglamentos para que no retengan más el dinero de los clientes.

El efecto perlocutivo, si fuera exitosa la fuerza ilocutiva de la carta como macroacto de habla directivo, sería la desaparición de las retenciones del dinero de las pensiones.

\section{Carta número 3: Actitud y progreso}

Un análisis de la conducta de las personas de los países ricos revela que la mayoría de ellos observan lineamientos que empiezan con la moral como principio básico, seguida por orden, limpieza, integridad, puntualidad, responsabilidad, deseo de superación, respeto a leyes $y$ reglamentos, respeto al derecho ajeno, amor al trabajo y esfuerzo. La actitud de las personas hace la diferencia.

Parece utilizar sólo un asertivo: "Un análisis de la conducta de las personas de los países ricos revela que la mayoría de ellos observan lineamientos que empiezan con la moral como principio básico, seguida por orden, limpieza, integridad, puntualidad, responsabilidad, deseo de superación, respeto a leyes y reglamentos, respeto al derecho ajeno, amor al trabajo y esfuerzo". Pero seguidamente se da un acto de habla expresivo: "La actitud de las personas hace la diferencia". Es decir: Yo opino que + este tipo de actitudes en las personas hace la diferencia.

Se puede obtener por inferencia un acto de habla directivo, que motiva realmente el envío de la carta por parte del remitente: Los costarricenses debemos seguir normas de comportamiento cívico para alcanzar el 'desarrollo'.

\section{Carta número 4: Civismo}

El club de Leones de Barrio Córdoba, el Centro Comercial del Sur, el Liceo Castro Madriz y el kínder de la Escuela Naciones Unidas organizaron una actividad llena de civismo el pasado 14 de septiembre. Entre otros, destacó el maestro Gerardo Mora, quien dirigió el canto de los himnos, los bailes folclóricos y el recibimiento de la antorcha, en el cual destacó el cuerpo de tambores.

Inicia con un acto de habla asertivo: "El club de Leones de Barrio Córboba, el Centro Comercial del Sur, el Liceo Castro Madriz y el kínder de la Escuela Naciones Unidas organizaron una actividad llena de civismo el pasado 14 de septiembre". Seguidamente se cumple un acto de habla expresivo, elogiar a uno de los organizadores de la actividad: "Entre otros, destacó el maestro Gerardo Mora, quien dirigió 
el canto de los himnos, los bailes folclóricos y el recibimiento de la antorcha, en el cual destacó el cuerpo de tambores". Para poner en mayor evidencia el acto de habla expresivo, incorporemos el verbo implícito: Elogio + la participación destacada de...

El efecto perlocutivo en los lectores de la carta como macroacto de habla expresivo radicaría en creer en la sinceridad del elogio proferido por el enunciador.

\section{Carta número 5: Golpe Bajo}

No es posible que después de que celebráramos el día de la Virgen de los Ángeles, las autoridades permitieran el encuentro mundial con el anticristo Jesús Miranda. Señores: No por ser un país democrático se puede permitir todo. Si otros países le cierran las puertas "¿Por qué aquí no? La plata no lo es todo $y$ esperamos que esa no haya sido la causa por la que se permiten tales actividades, así como haya sido la última vez que tal cosa suceda.

Inicia con un acto de habla expresivo: "No es posible que después de que celebráramos el día de la Virgen de los Ángeles, las autoridades permitieran el encuentro mundial con el anticristo Jesús Miranda”. El verbo que mejor puede expresar este acto de habla expresivo es rechazar: Rechazo que + después de la celebración del día de la Virgen de los Ángeles, las autoridades permitieran el encuentro mundial con el anticristo Jesús Miranda.

Se plantea seguidamente un acto de habla directivo: "Señores: No por ser un país democrático se puede permitir todo". El verbo que mejor expresa este acto de habla es recomendar: Recomiendo que + ciertas acciones se prohíban, aunque vivamos en democracia.

Sigue un acto de habla asertivo: "Si otros países le cierran las puertas" y un acto de habla directivo indirecto formulado como pregunta retórica: “Por qué aquí no?”. Es decir, si en otros países se han tomado medidas para prohibir su ingreso (afirmación), en Costa Rica también debería ejecutarse la misma medida (recomendación).

Se cierra con un acto de habla asertivo: "La plata no lo es todo" y un acto de habla expresivo desiderativo: "y esperamos que esa no haya sido la causa por la que se permiten tales actividades, así como haya sido la última vez que tal cosa suceda".

Si fuera asumida este último por las autoridades de inmigración, el efecto perlocutivo de esta carta, considerada como macroacto de habla directivo, sería denegar en el futuro la entrada al país de personas con estos antecedentes.

\section{Carta número 6: ¿Seguridad?}

Soñé que disfrutaba de mi país con la libertad de cuando era niño. Que podía andar por calles $y$ parques sin preocupación, disfrutar de mi pueblo, pero desperté a una realidad de pesadilla: asaltos en las calles, en las viviendas, cuando conducimos, bajonazos a plena luz del sol y... ¿la Policía?". Cómo quisiera ver patrullas en las calles, casetillas de seguridad, policías de a pie que nos hagan sentir que no estamos en manos del hampa. El ministro de Seguridad prometió enviar la Policía a las calles, pero no la vemos. Quizás está en Limón cuidando a los turistas.

Inicia con un acto de habla asertivo: "Soñé que disfrutaba de mi país con la libertad de cuando era niño. Que podía andar por calles y parques sin preocupación, disfrutar de mi pueblo, pero desperté a una realidad de pesadilla: asaltos en las calles, en las viviendas, cuando conducimos, bajonazos a plena luz del sol y... ¿la Policía?". Se describe un sueño y la realidad de la vigilia: en estas circunstancias, se busca certificar (asertivo), mediante la descripción, la antítesis de ambas realidades: la deseable y la real. El verbo que mejor expresa este acto de habla es afirmar: Afirmo que + la sociedad está desprotegida frente a los delincuentes.

A continuación se expresa un acto de habla directivo desiderativo: "Cómo quisiera ver patrullas en las calles, casetillas de seguridad, policías de a pie que nos hagan sentir que no estamos en manos del hampa". El verbo que mejor expresa este acto de habla es querer: Yo quiero + ver a la policía en la calle cuidando de la ciudadanía. 
Se cierra con dos actos de habla asertivos que demuestran la falta de protección de la ciudadanía frente la delincuencia: el primero es "El ministro de Seguridad prometió enviar la Policía a las calles, pero no la vemos" y el segundo "Quizás está en Limón cuidando a los turistas".

El efecto perlocutivo de la carta radicaría en que, a raíz de su publicación, se ejecutarían las medidas necesarias para aumentar la protección policial de los ciudadanos.

\section{Carta número 7: Insensibilidad}

Es increíble a lo que hemos llegado. Caminaba a las 7 p.m. por las paradas de buses de San Rafael Abajo en San José cuando, casi a los pies de la gente que hacía fila para tomar el bus, un maleante forcejeaba en el suelo con un ebrio, al que trataba de 'bolsear'. Como pude, me abrí campo entre el tumulto y ahuyenté al depredador. Es increíble que ni hombres ni mujeres (todos jóvenes por cierto) se inmutaran ante tal descaro.

Se puede considerar como un macroacto de habla expresivo. Expresa la indignación por la indiferencia de los peatones ante el intento de robo contra una persona ebria por parte de un asaltante. La carta comienza con un acto de habla expresivo: "Es increíble a lo que hemos llegado". Por inferencia, el verbo expresivo que mejor expresa este enunciado es repudiar: Yo repudio + las situaciones a las que hemos llegado en Costa Rica.

Seguidamente aparece el acto de habla asertivo, es decir, la descripción del hecho que provoca la indignación: "Caminaba a las 7 p.m. por las paradas de buses de San Rafael Abajo en San José cuando, casi a los pies de la gente que hacía fila para tomar el bus, un maleante forcejeaba en el suelo con un ebrio, al que trataba de 'bolsear'. Como pude, me abrí campo entre el tumulto y ahuyenté al depredador". Es decir: Yo declaro que + caminaba a las, etc.

Por último, aparece el acto de habla expresivo: "Es increíble que ni hombres ni mujeres (todos jóvenes por cierto) se inmutaran ante tal descaro". De nuevo el verbo expresivo que mejor expresa este enunciado es repudiar: Yo repudio + la indiferencia de los ciudadanos ante estos hechos delictivos.

También podemos inferir un acto de habla directivo implícito, hacia el que están orientados los demás actos de habla: Modifiquemos nuestras actitudes y comportamientos para defender a toda víctima que sea atacada por la delincuencia.

El efecto perlocutivo de la carta como macroacto de habla expresivo radicaría no sólo en que los lectores crean en la sinceridad de la indignación verbalizada por el enunciador. El efecto perlocutivo del acto de habla directivo, si fuera exitoso en los lectores, sería que estos últimos reaccionen a partir de ahora en favor de toda víctima agredida por la delincuencia.

\section{Carta número 8}

A principios de la década de 1980, los sindicatos bancarios y el del INS, agrupados en la Federación de Empleados Bancarios $y$ de Seguros, que presidí por varios años, nos opusimos férreamente $y$ nos manifestamos en varias ocasiones contra los intentos de desnacionalizar la banca estatal $y$ de fortalecer la privada. Se dio la desnacionalización y la banca estatal se vio obligada a superarse, rectificando yerros y fortaleciéndose. Hoy está plenamente consolidada y con utilidades jamás imaginadas. ¡Cuán equivocados estábamos!

Equivocados comienza con un acto de habla asertivo: "A principios de la década de 1980, los sindicatos bancarios y el del INS, agrupados en la Federación de Empleados Bancarios y de Seguros, que presidí por varios años, nos opusimos férreamente $y$ nos manifestamos en varias ocasiones contra los intentos de desnacionalizar la banca estatal y de fortalecer la privada. Se dio la desnacionalización y la banca estatal se vio obligada a superarse, rectificando yerros y fortaleciéndose. Hoy está plenamente consolidada y con utilidades jamás imaginadas". El enunciador afirma que, en su día, se opuso al surgimiento de la banca privada, con 
la preocupación de que contribuiría a la desaparición de la pública. Pero el enunciador certifica (aserción) que veinte años después, como consecuencia de esta decisión, la banca pública se encuentra más fortalecida.

Seguidamente se enuncia un acto de habla expresivo: "¡Cuán equivocados estábamos!" El verbo que permite identificar este acto de habla es reconocer: Reconozco que + estábamos equivocados. El enunciador reconoce un error de apreciación: se retracta, en la actualidad, de una posición ideológica asumida veinte años antes.

El efecto perlocutivo de esta carta, si es exitoso, radicará en que el lector acepte las disculpas ofrecidas por el enunciador al reconocer que la apertura de la banca pública ha sido exitosa.

\section{Carta número 9: En el San Juan de Dios}

Hago un respetuoso pero vehemente llamado a las autoridades del Hospital San Juan de Dios para que se facilite la visita de personas de la tercera edad a los pacientes internados. Ha sido muy difícil para mi padre, de 80 años, con 52 de casado, con mi madre internada por 20 días, hacer fila hasta por 3 horas con tal de verla y acompañarla.

En el San Juan de Dios es una de las escasas oportunidades donde se utiliza explícitamente un acto de habla directivo, aunque amortiguado por una marca de cortesía. El verbo utilizado en este caso es pedir o realizar un llamamiento: "Hago un respetuoso pero vehemente llamado a las autoridades del Hospital San Juan de Dios para que se facilite la visita de personas de la tercera edad a los pacientes internados".

Seguidamente se expresa el acto de habla asertivo que motiva el pedido previo: "Ha sido muy difícil para mi padre, de 80 años, con 52 de casado, con mi madre internada por 20 días, hacer fila hasta por 3 horas con tal de verla $y$ acompañarla”. El efecto perlocutivo sólo será exitoso si las autoridades del hospital cambian el reglamento del hospital para permitir la ampliación de los horarios de visitas a los enfermos.

\section{Carta número 10: Animal indefenso}

El señor Guillermo Vargas, conocido por algunos como Habacuc, cometió un crimen contra un indefenso animal, que utilizó para sus propósitos personales en una exposición realizada en Nicaragua. Este crimen atroz no merece menos que cárcel. Por eso los ticos estaremos atentos a las denuncias formales en los tribunales de nuestro país o en Nicaragua.

Inicia con un asertivo, la descripción de la acción que el enunciador considera como delito: Afirmo que + El señor Guillermo Vargas, conocido por algunos como Habacuc, cometió un crimen contra un indefenso animal, que utilizó para sus propósitos personales en una exposición realizada en Nicaragua.

Seguidamente aparece el acto de habla expresivo: Opino que + este crimen atroz no merece menos que cárcel.

Seguidamente se utiliza un promisorio: Prestaremos atención + a las denuncias formales en los tribunales de nuestro país o en Nicaragua para que este tipo de crímenes no queden impunes. Los promisorios son escasos en las cartas al editor. La mayor parte de los remitentes escriben para denunciar (asertivo) una situación evaluada negativamente para que otras personas tomen acciones (directivo). No es común leer cartas en las que el propio enunciador se comprometa a tomar acciones.

El efecto perlocutivo de esta carta en el lector, como macroacto de habla, radica en que el destinatario crea en la sinceridad de las intenciones del enunciador.

\section{CONCLUSIONES}

Los lectores hablan como ciudadanos (es el caso de El azul de la bandera, Actitud y progreso, Civismo y ¿Seguridad?), como usuarios de un servicio público (En el San Juan de Dios), como clientes (Ahorro detenido), como funcionarios (Equivocados), como feligreses (Golpe bajo), como defensores de los derechos de los animales (Animal indefenso), y como ciudadano-transeúnte (Insensibilidad). 
La intencionalidad de la mayor parte de las cartas se orienta hacia las quejas sobre una situación evaluada negativamente y las recomendaciones para su solución. Los actos de habla asertivos (demostrar una situación) y expresivos (evaluar negativamente esta situación) están al servicio de la solicitud (directivo) para cambiar situaciones consideradas como perjudiciales para los individuos y para la sociedad. Ahora bien, en la mayor parte de las ocasiones los actos de habla directivos están implícitos. La cortesía motiva esta situación. Debe destacarse, como señalan Calsamiglia y Tusón (2004: 200), que a la hora de formular actos de habla directivos, "lo más común es que las personas utilicen formas indirectas $y$ no formas directas", situación que confirman García Negroni y Tordesillas Colado (2001: 141). Literalmente se suele expresar una queja, cuando indirectamente el remitente está aconsejando la toma de medidas para la desaparición de la situación.

Se comprueba que los remitentes no piden reformas socio-estructurales. Sólo proponen reformar situaciones específicas en las que, como participantes, se consideran afectados. En común ver remitentes de cartas que, en su papel de clientes, critican el desempeño de un empleado: es el caso 'En el restaurante X el empleado Y me habló de mal modo...”. En estos casos, se denuncian a personas con precarias situaciones laborales que carecen de todo poder para responder $y$ defenderse. En pocas ocasiones, en suma, se redactan cartas perfiladas desde los intereses de clase.

Es posible que sea nulo el efecto perlocutivo de las cartas, teniendo presente que el macroacto de habla global de las cartas es generalmente directivo. No existe ningún mecanismo que permita monitorear la respuesta de los destinatarios a las reclamaciones previas de los lectores, aunque ocasionalmente respondan, como es el caso de los gerentes de empresas, para explicar que la situación criticada ha sido mejorada o, en cambio, para refutar las denuncias iniciales. Por otra parte, los enunciadores carecen de los medios, por lo general, para verificar que la queja ha sido aceptada y se han tomado las medidas pertinentes para la eliminación de la situación criticada.
Por último, recomendamos la investigación de las nuevas modalidades de la comunicación epistolar periodística, que encuentran sobre todo nuevos canales de expresión con el surgimiento de Internet. Es el caso, por ejemplo, de Panorama Mundial, de CNN en español, que cuenta con una sección de correo electrónico con mensajes enviados desde América Latina.

\section{BIBLIOGRAFÍA}

Austin, John L. Cómo hacer cosas con palabras. Barcelona, España: Editorial Paidós, 1971.

Calsamiglia Blancafort, Helena y Amparo Tusón Valls. Las cosas del decir. Manual de análisis del discurso. Barcelona: Editorial Ariel, 2004.

Cozort Renfro, Paula. "Bias in selection of letters to editor". Journalism Quarterly 56 (4). 1979: 822-6.

Ericson, Richard V.; Patricia M. Baranek y Janet B.L. Chan. Negociating control. A study of news sources. Milton Keynes, England: Open University Press, 1989.

Forsythe, Sidney A. "An exploratory study of letters to the editor and their contributors". Public Opinion Quarterly 14 (1). 1950: 143-4.

García Negroni, María Marta y Marta Tordesillas Colado. La enunciación en la lengua: de la deixis a la polifonía. Madrid: Gredos, 2001.

Hall, Stuart; Critcher, C.; Jefferson, T.; Clarke, J. y Roberts, B. Policing the crisis. Mugging, the state, and law and order. Londres: MacMillan, 1978.

Hernández Toribio, María Isabel. El poder de la palabra en la publicidad de radio. Barcelona: Editorial Octaedro, 2006. 
Herrera Damas, Susana. "Tipología de la participación de los oyentes en los programas de radio". Revista Anàlisi 30. 2003: 145-166.

Kerbrat-Orecchioni, Catherine. "Acto de lenguaje". Patrick Charaudeau y Dominique Maingueneau (dirs.). Diccionario de análisis del discurso. Buenos Aires, Argentina: Amorrortu editores, 2005: 12-15.

"Acto de lenguaje indirecto". Patrick Charaudeau y Dominique Maingueneau (dirs.). Diccionario de análisis del discurso. Buenos Aires, Argentina: Amorrortu editores, 2005: 15-17.

Lemert, James B. and Jerome P. Larkin. "Some reasons why mobilizing information fails to be in letters to the editor". Journalism Quarterly 56 (3). 1979: 505-12.

Lineros Quintero, Rocío. "El componente pragmático en el estudio lingüístico del discurso: los actos de habla publicitarios". Perspectivas pragmáticas en lingüística aplicada. 1998: 153-161.
Maingueneau, Dominique. Initiation aux méthodes d'analyse du discours. Paris: Hachette, 1976.

Núñez Aldasoro, Antonio J. “¿Defensor de los lectores o del diario?" Comunicación. Estudios venezolanos de comunicación 111. 2000: 32-39.

Pericot, Jordi. Mostrar para decir. La imagen en contexto. Barcelona: Universitat Autònoma de Barcelona, 2002.

Schiffrin, Deborah. Approaches to discourse. Oxford: Blackwell, 1994.

Searle, John. Actos de habla. Madrid, España: Editorial Cátedra, 1994.

Singletary, Michael. "How public perceives letter to the editor". Journalism Quarterly 53 (3). 1976: 535-7.

Winocur, Rosalía. Ciudadanos mediáticos. La construcción de lo público en la radio. Barcelona, España: Editorial Gedisa, 2002. 